\title{
THE EFFECT OF ATROPINE AND NEOSTIGMINE ON CARDIAC RATE AND RHYTHM DURING METHOXYFLURANE AND HALOTHANE ANAESTHESIA
}

\author{
J. W. R. MCINTYRE, F.F.A.R.C.S., AND G. DRUMMOND,|A.B.B., B.CH. ${ }^{*}$
}

NEUROMUSCULAR BLOCKING AGENTS are combined with a variety of anaesthetic drugs and at the termination of surgery neostigmine is frequently used to reverse their residual activity. Clinical investigators of halothane comment on the hypersensitivity of the heart to the cardio-inhibitory effects of neostigmime ${ }^{1,2}$ and advise that prior to its administration halothane should be washed out of the body or at least reduced to a negligible concentration. In addition adequate atropinization should be assured. ${ }^{3}$ Cessation of halothane administration before the end of the operation can produce inconvenient responses in a patient only partially curarized, and waiting in the operating room while the halothane is eliminated and the neostigmine given causes an undesirable delay. Methoxyllurane is a potent volatile fluorinated hydrocarbon possessing certain attractive fểatures for general anaesthesia, and the purpose of this investigation is to determine the effect of neostigmine on the cardiac rate and rhythm during halothane and methoxyflurane anaesthesia.

\section{Method}

None of the patients suffered from any pre-operative respiratory disease or cardiac arrhythmias. Operations varied in length from $1 \frac{11}{2}$ to 7 hours and. a standard anaesthetic technique was used. This consisted of a thiopentone and succinylcholine induction, intubation, and maintenance with a $2 \mathrm{~L} . / \mathrm{min}$. flow of nitrous oxide and oxygen 1:1 and 0.5-1.0 per cent halothane or 1.0-1.5 per cent methoxyHlurane into a semi-closed absorber system. Curare or gallamine was administered irrespective of the duration of surgery, and if bradycardia below 60 per minute developed.during the operation, "atropine was given as indicated. This was rarely necessary except when halothane and curare were used. A pressurecycled respirator and Wright spirometer provided artificial ventilation adjusted to minute volumes based on 25-50 per cent in excess of the Radford nomogram. ${ }^{4}$ This has been found to màintain the $\mathrm{pH}, \mathrm{pCO}_{2}$, and $\mathrm{HCO}_{3}$ at normal to alkalotic levels $s^{5}$ and this was confirmed during this series by random estimations.

At the final stage of the operation during the suture of muscle, subcutaneous tissues, and skin, atropine was administered intravenously in dosage varying from 0.6 to $1.8 \mathrm{mg}$. (0.0040-0.01 mg. per lb. body weight) and the E.C.G. recorded at the termination of the four subsequent minutes. At the termination of the fourth minute neostigmine $0.01 \mathrm{mg}$./lb. was given. The E.C.G. was again recorded at the termination of the ten succeeding minutes. The effect on the tidal volume and blood pressure was also noted. When the pulse rate fell to 60 per minute atropine $0.6 \mathrm{mg}$. was administered and repeated if necessary.

'Department of Anaesthesia, University of Alberta Hospital, Edmonton, Alberta. 


\section{ResULTS}

Arrhythmias were infrequent and transient. The Imost common associated with neostigmine during methoxyflurane' anaesthesia was the change from sinus to auriculoventricular rhythm with synchronization. This occurred in four cases between the fifth and tenth minute after administration and there was a minimal increase in pulse rate at this time. In one case $A-V$ rhythm that had been unaffected by the preneostigmine administration of atropine returned to sinus rhythm. Similar changes occurred during halothane anaesthesia, A-V rhythm with synchronization occurring in four cases and $\mathrm{A}-\mathrm{V}$ rhythm converting to sinus rhythm in three.

The initial dose of atropine produced A-V rhythm by the end of the first minute in two cases anaesthetized with halothane and two with methoxyflurane. Atropine given to counteract a bradycardia of 60 per minute was associated with A-V rhythm and synchronization in one case anaesthetized with halothane, while methoxyllurane was associated with $\mathrm{A}-\mathrm{V}$ rhythm land synchronization in two cases and nodal extrasystoles in a third.

TABLE I

Effects of Atropine and Neostigmine on Cardiac Rhýthm

\begin{tabular}{|c|c|c|c|c|c|c|}
\hline \multirow{3}{*}{$\begin{array}{l}\text { Halothane, curare } \\
\text { Halothane, gallamine }\end{array}$} & \multirow{3}{*}{$\begin{array}{c}\begin{array}{c}\text { No. of } \\
\text { cases }\end{array} \\
15 \\
17\end{array}$} & \multicolumn{2}{|c|}{ Atropine dosage, mg./lb. } & \multirow{3}{*}{ 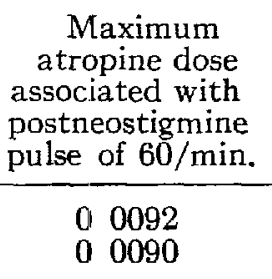 } & \multirow{2}{*}{\multicolumn{2}{|c|}{$\begin{array}{l}\text { Number of cases } \\
\text { developing pulse } \\
\text { of } 60 / \mathrm{min} \text {. }\end{array}$}} \\
\hline & & \multirow{2}{*}{$\begin{array}{cc}\text { Average } \\
0 & 0067 \\
0 & 0059\end{array}$} & \multirow{2}{*}{\begin{tabular}{cc}
\multicolumn{2}{c}{ Range } \\
0 & $0040-0.0100$ \\
0 & $0040-0.0090$
\end{tabular}} & & & \\
\hline & & & & & $\begin{array}{r}8 \\
11\end{array}$ & $594 \%$ \\
\hline $\begin{array}{l}\mathrm{M}-\mathrm{O}-\mathrm{F}, \text { curare } \\
\mathrm{M}-\mathrm{O}-\mathrm{F} \text {, gallamine }\end{array}$ & $\begin{array}{l}15 \\
16\end{array}$ & $\begin{array}{ll}0 & 0049 \\
0 & 0059\end{array}$ & \begin{tabular}{lll|l}
0 & $0037-0$ & 0063 \\
0 & $0046-0$ & 0075
\end{tabular} & $\begin{array}{ll}0 & 0057 \\
0 & 0075\end{array}$ & $\begin{array}{l}2 \\
4\end{array}$ & $\begin{array}{l}1935 \% \\
\text { S.D. } 1121\end{array}$ \\
\hline
\end{tabular}

Details of the atropine dosage and the number of patients whose pulse rate fell to 60 per minute appear in Table I. These changes developed gradually, the rate of 60 being reached four to ten minutes after the administration of the neostigmine. The relationship of pre- and post-atropine pulse rate to the postneostigmine pulse rate appears in Figures $1-4$.

Any fall in blood pressure that occurred was associated with bradycardia, and vasopressors were never required. There was usually little change in the tidal volume and it was never reduced below the Radford nomogram value for the particular patient.

\section{Discussion}

Neostigmine was described by Aeschlimann in $1931^{6}$ and its acetylcholinepotentiating properties are the result of a reversible inhibition of the choline esterases, binding both to the anionic and esteratic sites. ${ }^{7}$ Using a heart-lung preparation of the dog it has been shown that the drug diminishes the heart rate, decreases the cardiac output, and raises the central venous pressure. Responses to vagal stimulation are more marked and occasional ventricular irregularities 
Postatropine pulserate/minute

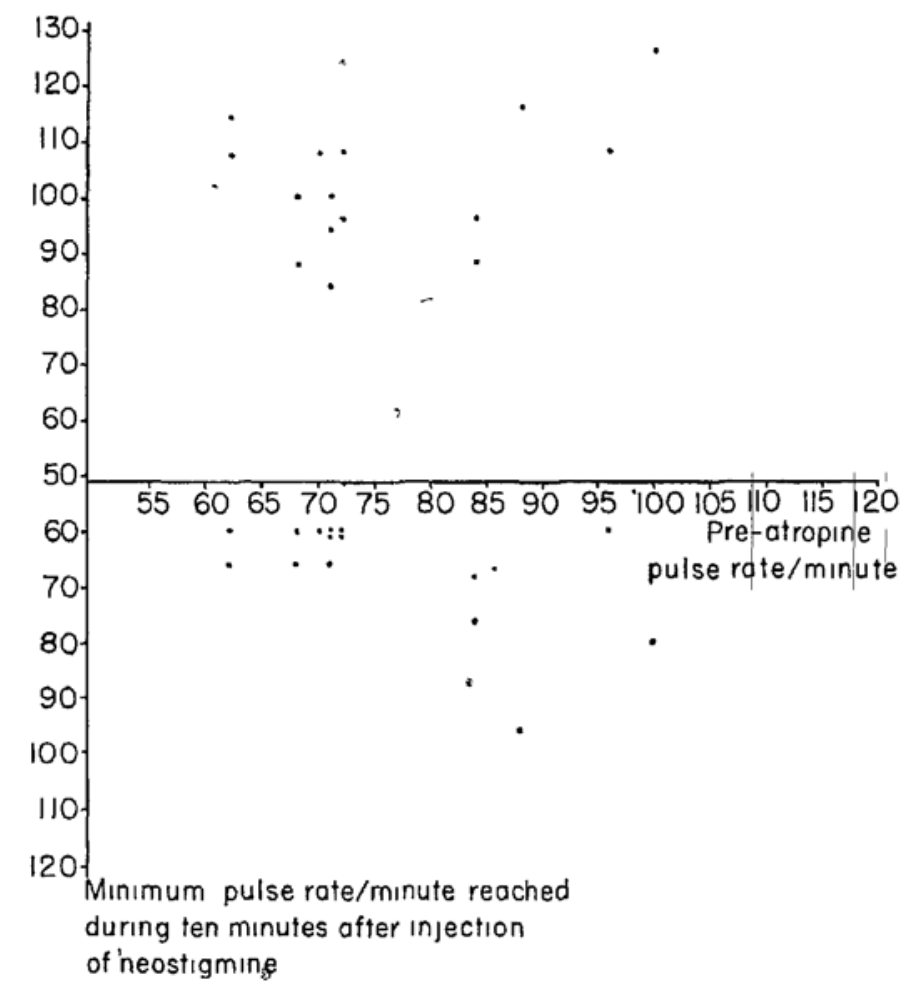

Figure 1. Halothane and curare.

Postatropıne pulse rate/minute

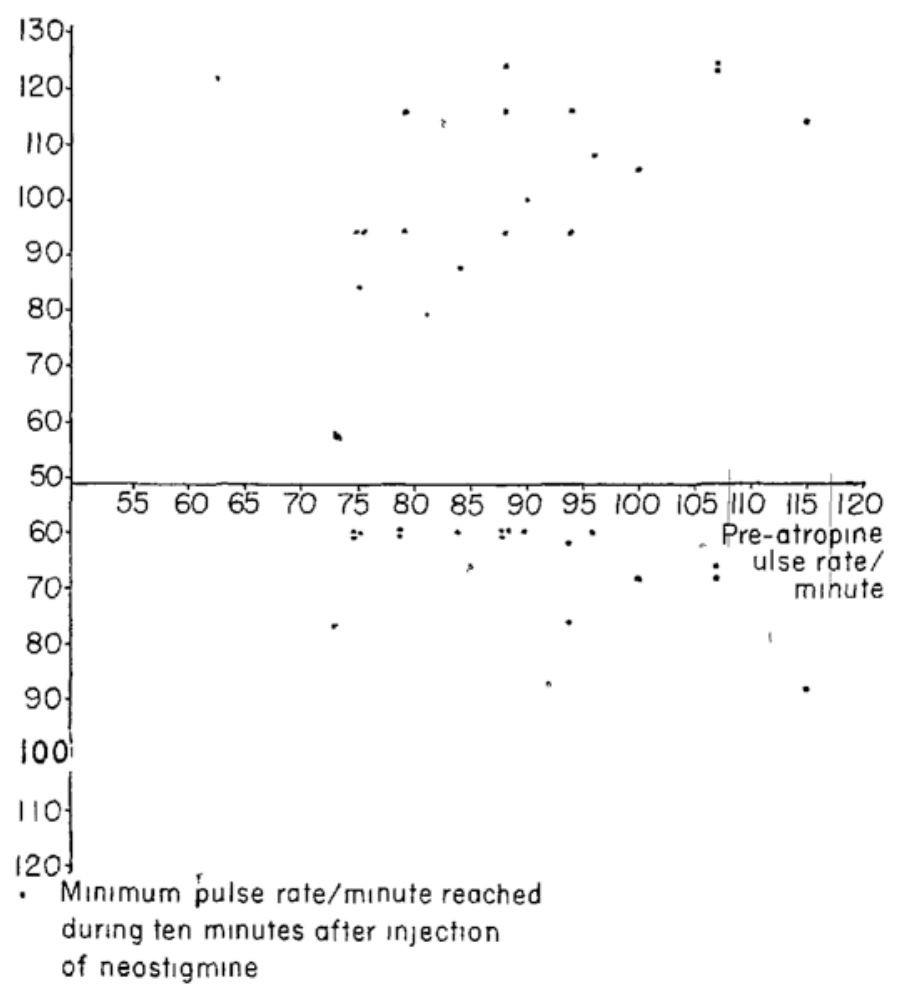

Frgure 2. Halothane and gallamine, 
Postatropine pulse rate/minute

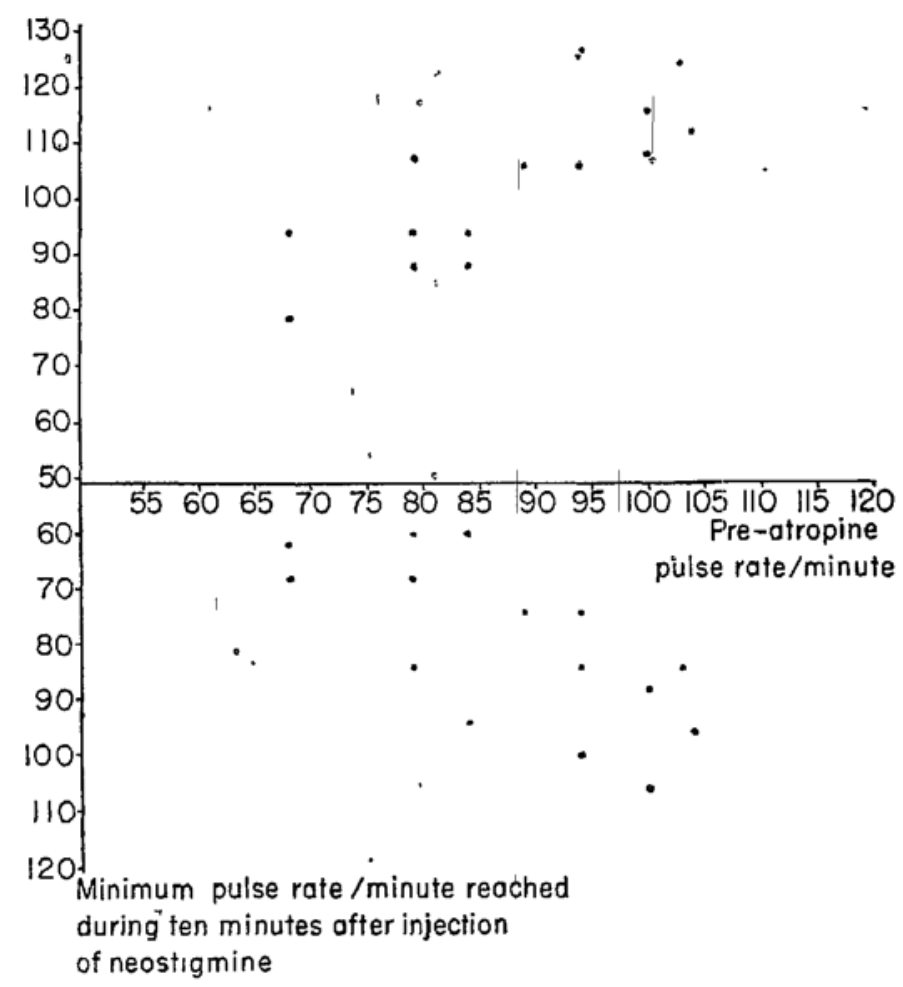

Figure 3. Methoxyflurane and curare.

Postatropine puise rate/minute

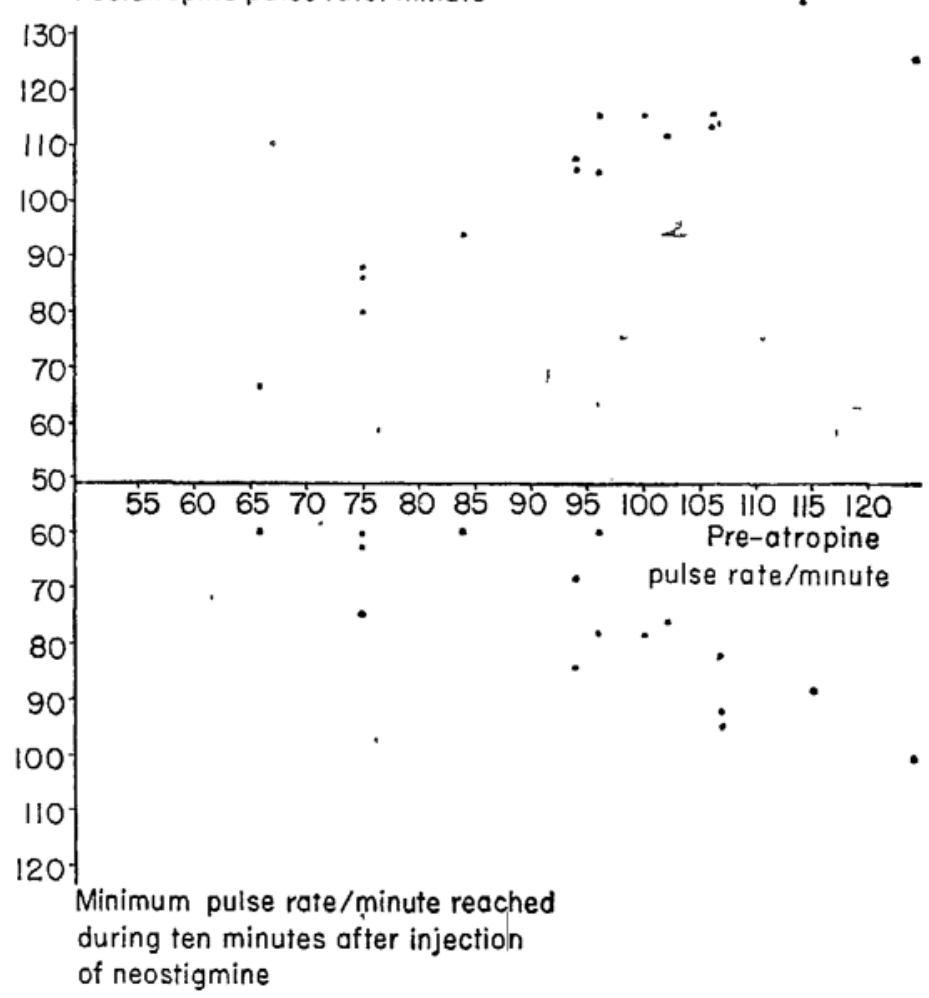

Ficure 4. Methoxyflurane and gallamine. 


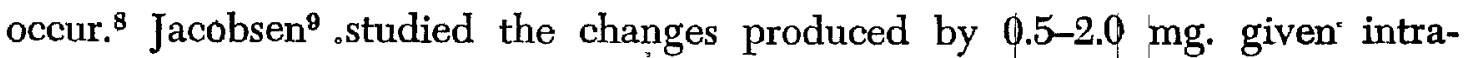
venously to patients anaesthetized with cyclopropane. No striking alteration in blood pressure occurred but changes such as sinus bradycardia; first-degree $\mathrm{A}-\mathrm{V}$ block, and increased amplitude of QRS and $T$ were observed in every case, and similar changes are reported in the present series. Gottlieb ${ }^{10}$ reported no changes following neostigmine administration during nitrous oxide and oxygen, ether, cyclopropane, and halothane anaesthesia except bradycardia, sometimes to a rate less than 50 per minute. In vitro studies with neostigmine have shown that 90 per cent of its maximum cholinesterase-inhibiting activity has been reached in five minutes and in ten minutes the maximum effect has been reached. ${ }^{11}$ This is in keeping with clinical findings that the maximum bradycardia takes approximately this length of time to develop. When volume-cycled ventilators are used, the decreasing pulmonary compliance will increase the airway pressures, and the cardiac effects of the neostigmine may be augmented by the stimulation of pulmocardiac reflexes. In this series pressure-cycled ventilators werre used and although the pulmonary compliance sometimes decreased and the tidal volume fell to the appropriate Radford nomogram value there was no evidence that an increased airway pressure in certain parts of the lung elicited such a reflex, and it seems unlikely that changes in $\mathrm{pO}_{2}$ and $\mathrm{pCO}_{2}$ were responsible for these cardiac changes. Although hýpoventilation after the administration of neostigmine would produce a lower mean airway pressure and so avoid the possible danger of potentiating the cardiac effects of the drug, nevertheless Riding has demonstrated that cardiac arrhythmias àre more likely to occur when ventilation has been inadequate ${ }^{12}$ and the paucity of arrhythmias in the present study supports these findings.

Averill ${ }^{13}$ observed the electrocardiographic effects of $0.8-1.2 \mathrm{mg}$. atropine given intravenously to conscious humans. The most common changes vere $\mathrm{A}-\mathrm{V}$ dissociation with interference or synchronization, induced atrial rhythm, or $\mathrm{A}-\mathrm{V}$ block, occurring within 30 to 60 seconds of injection. The onset of A-V dissociation was considered to be related to individual differences in the balance between the early vagotónic effects of atropine-depressing the supranodal focus and an early selective action of the anticholinergic action of atropine on the ventricular conductive system. These changes occur prior to the fully developed increase in sinus rate. He suggested that if the vagotonic influence is intense enough the early release of a ventricular focus from vagal control may induce idioventricular rhythms. Similar changes were reported during halothane anaesthesia by Jones and his colleagues ${ }^{14}$ and by Gottlieb. ${ }^{10}$ In the present series all the changes produced by the atropine administered prior to the neostigmine appeared and disappeared within two minutes of the administration of the drug and by this time the peak increase in pulse rate had also been achieved. These changes were associated with an atropine dosage varying from 0.0040 to $0.0075 \mathrm{mg}$. $/ \mathrm{lb}$. body weight. The absence of ventricular rhythms is due to adequate ventilation with no alteration in rate or pressures and, except for the anaesthetic agents in use, no increase in myocardial irritability.

Additional atropine given to counteract an unexpectedlyi severe bradycardia induced by neostigmine might be expected to show evidence of a sudden release 
of sympathetic activity and Jacobsen, ${ }^{9}$ administering atropine at the peak of the neostigmine effect during cyclopropane anaesthesia, observed ventricular premature contractions and paroxysmal ventricular tachycardia. The relative stability of cardiac rhythm in the series anaesthetized with halothane or methoxyflurane is related to the more limited secretion of catecholamines and to adequate ventilation. In the light of Di Palma's postulate that hydrocarbons sensitize the heart to epinephrine by inhibiting its natural antagonist acetylcholine ${ }^{15}$ it might be thought that the administration of neostigmine exerted a protective effect against arrhythmias induced by subsequent injection of atropine. Certainly in four cases neostigmine was associated with a reversion from $A-V$ to sinus rhythm. However, it is in this group that the one instance of extrasystoles occurred, and Hoffman and his colleagues ${ }^{16}$ suggest that acetylcholine acts on certain intracardiac structures causing the liberation of epinephrine or some related sympathomimetic substance. This would make a further injection of atropine more hazardous.

There appeared to be a greater incidence of bradycardia to a rate of 60 per minute when gallamine was used instead of curare but this difference was not significant. Gallamine, because it blocks the cardio-inhibitory effect of vagal stimulation, has been suggested as the relaxant of choice to bej used with halothane. ${ }^{17}$ In the dog, bradycardia produced by acetylcholine is prevented by gallamine ${ }^{18}$ and it might be supposed that the use of the relaxant offers protection against neostigmine-induced bradycardia. The results presented indicate that in clinical practice this is not so, and support the work of Melville, ${ }^{19}$ who states that the response of cats and dogs to acetylcholine is depressed but not abolished, and Bovet, ${ }^{20}$ who observed little effect on the depressor response to acetylcholine. Cholinesterase activity is depressed a slight but equal amount by gallamine and by curare. ${ }^{21}$

Death due to the administration of atropine or neostigmine can occur in a variety of ways. The most rapid and dramatic onset is due to ventricular fibrillation induced by atropine. ${ }^{22}$ The final stages of more gradually developing complications probably take place in a recovery room or ward, may not be considered to be originally due to these drugs. Bradycardia may terminate in cardiac standstill. Atropine given to counteract an unexpectedly severe bradycardia may produce ventricular fibrillation. ${ }^{9}$ Auriculoventricular rhythm with or without synchronization produces a fall in systolic blood pressure and a rise in venous pressure. ${ }^{23}$ This is not usually a serious hazard but a fall in blood pressure at this time, for any reason, might be treated with a vasopressor, and depending on the choice of drug, more serious arrhythmias might be produced. Hunter has recorded the use of methylamphetamine under these circumstances. ${ }^{24}$

Considerable attention has been devoted to the avoidance of severe bradycardia, and Hunter ${ }^{24}$ and Boulton ${ }^{25}$ have observed that the slower the heart rate is before the atropine administration, the slower it eventually becomes after the neostigmine administration, presumably owing to the more rapidly diminishing effect of the atropine. The present findings are similar and also show that a large quantitative response to the atropine indicates the activity of the autonomic nervous system or level of circulating catecholamines rather than a suitable 
degree of protection against neostigmine-induced bradycardia. No arbitrary safe level of pulse rate could be determined and it appears that when atropine and neostigmine are to be administered the existing pulse rate should be considered, with reference to the probable amount of vagal tone, the catecholamine level, drugs affecting the pulse rate without blocking neostigmine-induced changes, and the level of myocardial irritability. Care should be taken to prevent hypercarbia, not to stimulate the pulmocardiac reflexes, and to avoid if $\mid$ possible the administration of additional atropine when thé peak neostigmine effect has been reached. The use of these drugs is a safe and valuable manouvre that has proved itself by clinical application, but attention to these details should reduce the small mortality associated with them. The pulse rate during methoxyflurane has been found to be significantly higher than during halothane anaesthesia ${ }^{26}$ and it is this negative chronotropic action of halothane on the heart which potentiates acetylcholine effects and renders it a less satisfactory drug than methoxyflurane to use in the presence of neostigmine.

\section{SUMMARY}

The effects on cardiac rhythm of atropine $0.0040-0.01 \mathrm{mg}$./lb. body weight followed in four minutes by neostigmine $0.01 \mathrm{mg}$./lb. body weight have been studied in patients anaesthetized with halothane and methoxyflurane.

The incidence of arrhythmias was small and there were no ventricular abnormalities. This is attributed in part to the ventilation of the subjects, which was based on a minute volume $25-50$ per cent in excess of the Radford nomogram.

Any slowing of the pulse below 60 per minute was treated at once with intravenous atropine. This complication was more common during halothane than methoxyflurane anaesthesia.

Gallamine in usual clinical dosage was found to exert no protective effect against neostigmine-induced bradycardia.

Attention was drawn to the relationship between the pulse rate prior to the administration of atropine and the rate eventually reached after the neostigmine, and the factors to be taken into consideration when atropine and neostigmine are to be used. The slower the pulse before the atropine, the slower it becomes after heostigmine.

The opinion is expressed that it is preferable to use neostigmine in the presence of methoxyflurane anaesthesia rather than halothane.

\section{RÉSUMÉ}

Chez des malades anesthésiés au fluothane et au méthoxyflurane, nous avons étudié les effets sur le rythme cardiaque de l'atropine à la dose de 0.004-0.01 $\mathrm{mg}$./lb. et de la néostigmine $0.01 \mathrm{mg}$./lb. de poids injectée quatre minutes après l'atropine.

Les arythmies' ont été rares et nous n'avons pas observé d'anomalies ventriculaires. La ventilation de ces malades était faite avec un volume/ninute excédant de 25 à 50 pour cent nomogramme de Radford, et c'est en plartie à cela que nous attribuons ces résultats. 
Tout ralentissement du pouls au-dessous de $60 / \mathrm{min}$. était corrigé immédiatement par une dose d'atropine par voie endoveineuse. Cette situation est apparue plus souvent au cours de l'anesthésie au fluothane qu'au cours de l'anesthésie au méthoxyflurane.

L'usage de la gallamine aux doses cliniques usuelles n'a pas semblé exercer d'effet protecteur contre la bradycardie provoquée par la néostigmine!

Nous avons porté une attention spéciale sur la vitesse du pouls avant l'administration de l'atropine, et la vitesse atteinte occasionnellement par le pouls après l'administration de néostigmine; nous signalons les facteurs à surveiller si l'atropine et la néostigmine doivent être employées. Plus le pouls est lent avant l'atropine, plus il devient lent après l'administration de néostigmine.

Nous sommes d'opinion qu'il est préférable d'employer la néostigmine avec le méthoxyflurane qu'avec le fluothane.

\section{REFERENCES}

1. Johnstone, M. Human Cardiovascular Response to Fluothane. Brit. J. Anaesth. 28: $392(1956)$.

2. Bryce-Smith, R. \& O’Brien, H. D. Some Obșervations on Fluothane. Proc. Roy. Soc. Med. 50: 193 (1957).

3. Wylte, W. D. \& Chưnchill-Davioson, H. C. A Practice of Anaesthesia. London: Lloyd Luke (1960).

4. Radfond, Edward P. Jr. Ventilation Standards for U\$e in Artificial Respiration. J. Appl. Physiol. 7: 451 (1955).

5. Garn, E. A. The Adequacy of the Radford Nomogram during Anaesthesia. Unpublished data.

6. Aeschlmann, John A. \& Reinert, Marc. The Pharmacological Action of Some Analogues of Physostigmine. J. Pharmacol. \& Exper. Therap. 43: 413 (1931).

7. Foldes, F. F.; Erdos, E. G.; Zsigmond, E. K.; \& Zwariz, J. A. Reactivation of Neostigmine Inhibited Human Plasma Cholinesterase. J.: Pharmacol. \& Exper. Therap. 129: 394 (1960).

8. Mendez, Rafael \& Ravin, Abe. The Action of Prostigmine on the Circulatory System. J. Pharmacol. \& Exper. Therap. 72: 80 (1941).

9. Jacobsen, Elliotr \& Adelman, Mrton H. The E.q.G. Eflects of Intravenous Administration of Neostigmine and Atropine during |Cyclopropane Anaesthesia. Anesthesiology 15: 407 (1954).

10. Gotzieb, Joel D. \& Sweet, Robert B. The Antagonism of Curare: The Cardiac Effects of Atropine and Neostigmine. Canad. Anaesth. Soc. T. 10: 114 (1963).

11. Smith, Cedric M.; Mead, James C.; \& Unna, Klaus R. Antagonism of Tubocurarine III. J. Pharmacol. \& Exper. Therap. 120: 215 (1957).

12. Rming, J. E. \& Robinson, J. S. The Safety of Neostigmine. Anaesthesia 16: 346 (1961).

13. Averm, L, K. H. \& Lamb, L. E. Less Commonly Recognuzed Actions of Atropine on Cardiac Rhythm. Am. J. Med. Sc. 237: 304 (1959).

14. Jones, R. E.; Deutsch, S.; \& TuRndorF, H. Effects of Atropine on Cardiac Rhythm in Conscious and Anaesthetized Man. Anesthesiology 22: 67 (1961).

15. Di Palma, Josepr R. The Role of Acetyl Choline in Hydrocarbon Epinephrine Arrhythmias. J. Pharmacol. \& Exper. Therap. 116: 255 (1956).

16. Hoffman, F.; Hoffman, E. J.; Mmdleton, S.; \& Telesnik, J. Stimulating Effect of Acetyl Choline on the Mammalian Heart and Liberation of Epinephrine-like Substance by Isolated Heart. Am. J. Physiol. 144; 189 (1945).

17. Burn, J. H.; Erstein, H. G.; Fetgan, J. A.; \& Paton, W. D. Some Pharmacological Actions of Fluothane. Brit. Med. J. 2: 479 (1957).

18. Riker, Walter F. \& Wescoe, W. Clarke. The Pharmacology of Flaxedil with Observations on Certain Analogs. Ann. N.Y. Acad. Sci. 54: 373 1951).

19. Melville, K. I. Discussion. Ann. N.Y. Acad. Sci. 54: 392 (1951). 
20. Bovet, D.; Depierre, F.; \& Lestrange, Y. De. (Quoted by Melvirte, K. I.) Compt. rend, acad. sci. 225: 74 (1947).

21. Foldes, Francis F.; BaArt, Nora; Shanor, Sydney P.; \& Erdos, Erying. The Inhubitory Effect of Neuromuscular Blocking Agents and Therr Antagonists on Human Cholinesterases. Anesthesiology 18: 163 (1957).

22. Johnstone, M. General Anaesthesia and Cardiac Inhibition. Brit. Heart J. 13: 47 (1951).

23. Laver, Mrron B. \& Turndorf, Herman. Atrial Activity during Halothane Anaesthesia. Anesthesiology 24: 133 (1963).

24. Hunter, A. R. The Anticurare Agents. Brit. Med. J. I: 640 (1953).

25. Boulton, Tom B. Cardiac Arrest following the Administration of Neostigmine. Brit. J. Anaesth. 28: 449 (1956).

26. Walker, Joe A.; Eggers, G. W. N. Jr.; \& Allen, Charles R. Cardiovascular Effects of Methoxyflurane. Anesthesiology 22: 639 (1963). 